\title{
Reflexões sobre a experiência formativa na plataforma freire em cursos de licenciatura em geografia
}

\author{
Reflections on the training experience at the freire platform in \\ geography courses
}

\author{
Agripino Souza Coelho Netol, Patricia Julia Souza Coelholl
}

\begin{abstract}
RESUMO
O texto objetiva compreender as trajetórias dos discentes de Geografia do Plano Nacional de Formação dos Professores da Educação Básica (PARFOR), identificando suas dificuldades e suas aprendizagens, bem como, apontar algumas contribuições que o referido programa trouxe para formação profissional dos envolvidos. Para apoiar esta reflexão, nutrimo-nos de dois procedimentos metodológicos: (i) das observações e das impressões obtidas pela experiência como docentes dos cursos e (ii) pela aplicação de um questionário aos discentes. Concluímos que, mesmo com os problemas enfrentados pelo PARFOR, não podem ser desconsideradas as mudanças qualitativas na vida e na trajetória formativa dos professores-cursistas. O texto aponta a necessidade de realização de outros estudos sobre este importante programa de formação de professores, no sentido de investigar como os professores-cursistas ressignificaram sua prática pedagógica após essa experiência formativa, aprofundando a análise dos impactos da formação no cotidiano escolar e dos sentidos dessa experiência para os professores-cursistas.
\end{abstract}

Palavras-chave: Ensino de geografia; Formação docente; Plataforma Freire

\section{ABSTRACT}

The article aims to understand the trajectories of the Geography students of the National Training Programme for Basic Education Teachers (PARFOR), identifying their difficulties and their learnings, as well as pointing out some contributions the program has brought to the professional training of those enrolled. In order to support this reflection, a couple of methodological procedures were used: (i) the observations and impressions obtained by the students experiences as teachers of the courses and (ii) the application of a questionnaire to the students. The conclusion was that, even with the problems faced by PARFOR, the qualitative changes in the teacher-students' lives and formative trajectory can not be disregarded. The article indicates the need to carry out other studies on the programme in order to investigate how the teacher-students re-signified their pedagogical practice after this formative experience, deepening the analysis of the training impacts in their school experience.

Keywords: Geography teaching; Teacher training; Freire Platform

'Professor adjunto da Universidade do Estado da Bahia, Salvador, BA. E-mail: agscneto@uneb.br ORCID: https://orcid.org/00000003-3714-510X

"Professora assistente da Universidade do Estado da Bahia, Serrinha, BA. E-mail: pjs.coelho@hotmail.com ORCID: https://orcid.org/0000-0002-0299-1448 


\section{DAS OBSERVAÇÕES INTRODUTÓRIAS}

A construção deste texto atende a uma demanda de reflexão sobre a experiência formativa do Plano Nacional de Formação dos Professores da Educação Básica (PARFOR), mais conhecido como Plataforma Freire. Nesse sentido, objetiva-se compreender as trajetórias dos discentes, identificando suas dificuldades e suas aprendizagens, bem como, apontar algumas contribuições que o referido programa trouxe para formação profissional dos envolvidos.

Vale ressaltar que a Plataforma Freire é um programa de formação de professores desenvolvido pela Universidade do Estado da Bahia com financiamento do Governo Federal (mais especificamente da Coordenação de Aperfeiçoamento de Pessoal de Nível Superior - Capes). O Programa visa a oferecer um curso de licenciatura para professores que estão na sala de aula. Os Cursos de Licenciatura ofertados pelo PARFOR são inteiramente gratuitos e destinam-se aos docentes em exercício na rede pública de educação básica.

O propósito central do texto é realizar uma reflexão crítica e livre sobre o processo formativo que se desenrolou durante o curso de Licenciatura em Geografia, valendo-se da experiência dos autores como docentes em algumas disciplinas do cursoi.

Nossa inquietação decorre da dimensão que o PARFOR assumiu na Universidade do Estado da Bahia, sendo oferecido nos 24 campi que compõem a instituição. Desse modo, cabe interrogar: quais os resultados alcançados com essa experiência, em termos de contribuição para a formação profissional dos discentes? Quem são os sujeitos que participaram do Programa e que aprendizagens experimentaram? Quais as dificuldades enfrentadas pelos estudantes, uma vez que, um número significativo concluiu seu ensino médio há duas ou três décadas atrás?

Para apoiar esta reflexão, nutrimo-nos de dois procedimentos metodológicos: (i) das observações e das impressões obtidas pela experiência como docentes do curso 
e (ii) pela aplicação de um questionário aos discentes, denominados no âmbito do PARFOR (nomenclatura assumida também neste texto) como professores-cursistas ${ }^{i i}$.

Essa segunda etapa consistiu na aplicação de um questionário a 20 professorescursistas do PARFOR-Campus XI, na cidade de Serrinha (BA), representando uma amostra de 46,51\%, e 10 professores-cursistas do PARFOR-Campus XXIV, na cidade de Xique-Xique (BA), representando uma amostra de 71,43\%. O questionário buscou levantar o perfil dos discentes, interrogando sobre a natureza das dificuldades enfrentadas, a contribuição para formação acadêmica e as sugestões para qualificação do curso, enfim, permitiu que os sujeitos pesquisados fizessem uma avaliação dos significados da experiência no curso de Licenciatura em Geografia do Plano Nacional de Formação dos Professores da Educação Básica - Plataforma Freire.

Importante sinalizar que a realização da pesquisa sobre as duas realidades, Campus XI-Serrinha e Campus XXIV-Xique-Xique, permitiu adotar uma postura comparativa. Como atuamos também em outros municípios baianos (Alagoinhas, Salinas da Margarida e Teixeira de Freitas), as análises podem assumir um caráter mais geral e apontar questões relevantes que dizem respeito à Plataforma Freire de forma mais geral.

O curso de Geografia oferecido no Campus XI, na cidade de Serrinha, atendeu a estudantes de diversos municípios localizados no Território do Sisal. Trata-se de um recorte regional localizado no Nordeste da Bahia, em pleno semiárido baiano, que tem no cultivo e na cadeia produtiva do Sisal um componente estruturante de sua realidade social, econômica e cultural (COELHO NETO, 2011, 2013a). A cidade de Serrinha dá nome a uma microrregião geográfica do Instituto Brasileiro de Geografia e Estatística (IBGE), constituindo-se em cidade que exerce efeito de polarização no contexto regional, com população estimada para o ano de 2018, de 80.411 habitantes.

O curso de Geografia oferecido no Campus XXIV, na cidade de Xique-Xique, teve um alcance mais restrito, atendendo apenas a estudantes oriundos do próprio município. A cidade de Xique-Xique se localiza no Território de Identidade Irecê, 
situado no Centro-Norte Baiano, com população estimada para o ano de 2018, de 46.440 habitantes. Xique-xique se destaca pela posição geográfica na Bacia do Rio São Francisco, que exerce influência em sua economia e cultura (BAHIA, 2018).

Para efeito didático, o texto está estruturado em quatro seções. Nesta seção inicial, nos incumbimos de apresentar as indagações principais, os objetivos e os procedimentos metodológicos. Na segunda seção, optamos por fazer uma reflexão mais geral sobre o processo de produção do conhecimento e sua relação com a educação. Como está em avaliação uma experiência formativa, buscamos discutir de forma mais ampla o papel que o conhecimento e educação desempenham na sociedade. A pertinência dessa seção está na natureza da Plataforma Freire, que busca oferecer um arcabouço teórico-prático, ou seja, conhecimento viabilizado por meio do processo educativo. Trata-se, nesse sentido, da socialização do conhecimento produzido e sistematizado pela humanidade, que se efetiva através do referido programa institucional (parceria entre o Governo Federal e a Universidade). A terceira seção está centrada na leitura avaliativa da experiência formativa que ganhou corpo nos dois municípios baianos (e nos dois campi da Universidade do Estado da Bahia), destacando o perfil dos estudantes, as dificuldades encontradas e sugestões para qualificar o Programa. Na última seção, nos detemos às considerações finais, que não assumem um caráter fechado e conclusivo, mas servem para apontar novas questões e lacunas para novas reflexões acerca desta significativa experiência educativa.

\section{DO PAPEL E DOS SIGNIFICADOS DO CONHECIMENTO E DA EDUCAÇÃO}

No nosso ponto de vista, o conhecimento é a maior obra da humanidade, sendo, indiscutivelmente, um produto da história e um produto social, na medida em que resulta do esforço de compreensão do mundo e de compreensão do próprio ser humano. O conhecimento produzido tem se colocado a serviço de diversos 
propósitos, pois como obra humana, expressa a teleologia que funda a natureza do homem.

Independente da sua manifestação objetivada e das bases primeiras que lhes funda, constituem-se no esforço humano para dotar de inteligibilidade os seres, as coisas, os fenômenos, os processos, a existência. Razão, abstração, lógica, objetividade, emoção, sentidos, percepção e subjetividade, se reúnem para a construção dessa tarefa essencial na constituição da própria essência do homem, daquilo que o torna particular na diversidade da natureza: a produção do conhecimento de si, das coisas, entendidas não de forma dissociadas.

O conhecimento, transformado em técnica, alimenta a produção de objetos que incorporam a sofisticação como princípio e buscam, interminavelmente, satisfazer as infinitas demandas e necessidades que a humanidade erigiu. Esse domínio do conhecimento produziu um enorme repertório de objetos técnicos, utensílios, métodos de produção e os mais variados recursos colocados à disposição da sociedade contemporânea.

Mas não podemos esquecer que a história é produto dos homens, e que seu percurso reclama continuamente por interpretação. Essa possibilidade de leitura da trajetória da humanidade nos permite refletir sobre o que fizemos e construir alternativas para o futuro. A compreensão da história, com suas descobertas, revoluções, formas de organização social e político-territorial, modos de produção e suas visões de mundo em cada recorte tempo-espaço, são objetos de reflexão do conhecimento, que sistematiza ideias e organiza sistemas de compreensão.

Esse processo é que alimenta, impulsiona e possibilita o avanço das concepções de mundo, permite-nos continuar fazendo a história, mas amparados em novos fundamentos, mudando os rumos dos fatos e construindo novas formas de sociabilidade. Essa perspectiva pode assumir planos bastante diversos, significando a contestação dos esquemas de pensamento que conformaram o racismo, o machismo, o totalitarismo, o autoritarismo, o eurocentrismo e o próprio antropocentrismo. Refletir, discutir, dissecar os princípios fundadores desses 
fenômenos e reconstruir novas bases intelectuais que apoiarão novos comportamentos no âmbito da sociedade. Esta é uma trilha fundamental que se coloca para o conhecimento humano, e no nosso caso, mais especificamente, para a ciência e, em particular, para a geografia.

No nível mais imediato que nos diz respeito, é possível refletir sobre o papel do conhecimento em sua relação com a educação e sua importância fundante na produção do conhecimento da sociedade e do acesso ao conhecimento que a sociedade produz. A educação é, por princípio, o processo mais amplo de viabilizar o acesso ao conhecimento sistematizado que a sociedade produziu, e como esse conhecimento é, na essência, a interpretação do mundo e do ser humano, a educação torna-se a possibilidade de nos conhecer e de conhecer tudo o que nos cerca. Ela ocupa um lugar central na discussão dos grandes temas que exerceram um papel de centralidade na constituição do sujeito que produz história.

Conhecer é desvendar, na intimidade do real, a intimidade de nosso próprio ser, que cresce justamente porque a nossa ignorância vai se dissipando diante das perguntas e respostas construídas por nós, enquanto sujeitos entregues ao conhecimento, como dependência da compreensão de nosso ser no mundo. Se há um sentido de um dado objeto, não é somente ele que se torna conhecido, mas essencialmente o próprio sujeito, isto é, o conhecimento de algo é também, simultaneamente, um auto-conhecimento (GHEDIN, 2005, p. 141).

Consideradas essas ideias como factíveis de aceitação, fica reforçada a relevância do papel da educação na construção da sociedade, sua contribuição fulcral para construirmos novas formas de sociabilidade, e os pilares de uma sociedade mais justa, sem desigualdades, sem preconceitos, sem violação dos direitos e da condição humana. Essa perspectiva nos coloca um compromisso social de grande ordem, exigindo uma atuação na sociedade, a serviço de um novo edifício social, que não pode ser erigido sem a clareza do que queremos, portanto, dos nossos propósitos e dos componentes essenciais que vêm sendo construídos em nossas formações.

O conhecimento adquire e tem sentido na medida em que nos toca existencialmente. Indicamos que conhecer implica, por conta do próprio 
processo, uma ação política calcada no compromisso ético-político para com a sociedade. O conhecimento é essencialmente o processo de uma atividade política que deve conduzir o sujeito que o produz a um compromisso de transformação radical da sociedade [...] (GHEDIN, 2005, p. 144).

Nessa direção, todos nós, educadores, somos convocados a cumprir esse papel e passar a contribuir para pensar e fazer a história social e, simultaneamente, a história da educação, ancorados em outros parâmetros. A educação, como processo de viabilização do acesso ao saber sistematizado, produziu sua própria história, que carrega na sua esteira um conjunto de acepções, teorias, métodos e técnicas. A educação não abandonaria o viés tecnicista se não houvesse um esforço para compreendê-lo e se suas bases não fossem submetidas ao exame crítico. Esses procedimentos devem conduzir nossa caminhada nos diversos espaços que ocupamos em nossa trajetória profissional e de vida.

Todos aqueles que reconhecem a centralidade da educação na construção da sociedade devem refletir sobre as elocuções que foram apresentadas até aqui. As discussões acerca da natureza, essência e do papel da educação, devem nortear a prática de todos nós, profissionais de educação, reconhecer as limitações e as restritividades do apelo à técnica e reconhecer/valorizar a dimensão política e social da educação na condição de campo fundamental na construção social. Devemos pensar o percurso que o processo educacional tomou na humanidade, as concepções hegemônicas e hegemonizadas, a reverberação das acepções nas práticas educativas em seus diversos níveis e dimensões, as questões de ordem política, técnica, socioeconômica, cultural, espacial, jurídica, entre outras, que produzem determinações em todo processo educacional e educativo; aproximar e aprofundar nossas reflexões sobre as realidades locais/regionais de concretização do processo educativo, buscando respostas mais particulares para as diversas demandas, espacialmente localizadas. 
A chamada nova LDB, Lei de Diretrizes e Bases (Lei 9394/96), estabeleceu uma nova configuração territorial para a competência do processo educacional no país. Com o aporte da Constituição Federal de 1988, que reforça o municipalismo e promove a possibilidade de empoderamento do poder municipal, as atribuições da educação infantil e fundamental são assumidas por esta instância de poder. Embora muito timidamente estudadas, mas largamente conhecidas no plano das experiências vivenciadas por milhares de professores (as), as dificuldades enfrentadas por esses níveis de ensino são gigantescas e bastante graves, constituindo-se num grande obstáculo ao desenvolvimento social e político das sociedades locais. Diante do distanciamento administrativo dos órgãos competentes e do obscurecimento dos centros de produção de conhecimento, distantes das realidades regionais e locais, sobretudo no Nordeste brasileiro, acredito que a prática da pesquisa nas universidades espalhadas pelo interior da Bahia e do Brasil, especialmente os trabalhos de monografia e de estágios dos estudantes e as pesquisas institucionais dos professores, possam cumprir esse papel de aproximação e enfrentamento necessário dessa difícil e desafiadora realidade.

As diversas ciências parcelares produzem representações de mundo. Cada qual, dotada de especificidades, busca encontrar e construir seu modo particular de ver o mundo, sua identidade. Inúmeros pensadores sinalizam uma recente revalorização da espacialidade como categoria de interpretação da sociedade como é o caso de Soja (1993) -, processo que vem sendo chamado de virada espacial, pois, durante o século XIX e parte do século XX, assistiu-se à prevalência do tempo e ao esquecimento/negligenciamento do espaço no pensamento ocidental. A emergência de diversos fenômenos nas últimas décadas e os modos como os esforços de interpretação se erigem apontam claramente para uma retomada ou talvez uma valorização de categorias, que, se não são exclusividade de nenhuma ciência particular, foram apropriadas e desenvolvidas de modo muito próprio pela geografia: refiro-me à força explicativa, à eficácia operacional, 
além da intensificação do uso dos conceitos de espaço, região, lugar, território, paisagem e das chamadas tecnologias geográficas. Eles foram largamente utilizados por diversas ciências, mas têm encontrado eco em outros campos, a exemplo do planejamento e das políticas públicas, dos discursos políticos, mas também estão sendo acionados pelos movimentos sociais, como demonstrou Coelho Neto (2013b).

Neste sentido, esperamos que os formandos do Plano Nacional de Formação dos Professores da Educação Básica (PARFOR), possam estar comprometidos com a produção do conhecimento, tendo em vista os fenômenos educacionais materializados nos espaços educativos dos seus municípios de atuação e das localidades circunvizinhas, e exerçam o seu papel profissional com base em perspectivas e projetos que possam contribuir para a emancipação dos sujeitos marginalizados em nossa sociedade, considerando que precisamos assumir uma postura crítica, social e política libertária frente às demandas da nossa realidade.

\section{DAS REFLEXÕES SOBRE O PROCESSO FORMATIVO: PERFIL DOS} DISCENTES, TRAJETÓRIAS, DIFICULDADES E APRENDIZAGENS

\subsection{Dos sujeitos da pesquisa}

Os professores-cursistas do Campus XI, da Universidade do Estado da Bahia, localizado na cidade de Serrinha, são oriundos de diversos municípios do Território do Sisal, a exemplo de Serrinha, Araci, Lamarão, Santaluz, Biritinga, entre outros. Dos 20 professores-cursistas pesquisados no Campus XI-Serrinha, $55 \%$ nunca tinham feito nenhuma graduação. A totalidade dos que tinham apenas o ensino básico cursou o magistério. No entanto, um percentual significativo de discentes, $45 \%$, estava em sua segunda graduação: $89 \%$ deles tinham feito Pedagogia e 11 \%, Administração. Esses dados indicam uma 
estratégia dos professores-cursistas no sentido de expandir sua área de atuação, já que o Curso de Licenciatura em Pedagogia limita a atuação docente ao Ensino Fundamental I, no entanto, com a Licenciatura em Geografia eles podem atuar no Ensino Fundamental II e no Ensino Médio. Outro dado relevante é que entre os estudantes que já tinham uma graduação, $20 \%$ já haviam cursado uma especialização.

Entre os professores-cursistas, 65\% atuam em escolas urbanas e 35\%, em escolas rurais. Os dados apontaram que os professores-cursistas já detêm uma longa experiência em sala de aula. Todos(as) eles(as) possuem mais de 5 (cinco) anos de docência. Entretanto, a maioria já tem larga experiência docente, pois 40\% têm entre 10 e 20 anos de docência e 50\% têm acima de 20 anos de ensino (Tabela 01). Contudo, os dados ficam mais equilibrados quando investigamos a experiência docente na disciplina Geografia, pois 45\% têm menos de 5 anos de ensino nesta área e 55\% ultrapassam 5 anos, sendo que 30\% destes últimos têm mais de 10 anos ensinando Geografia (Tabela 02). Esses dados nos informam que um número significativo de cursistas estava atuando como professores de Geografia mesmo sem uma graduação na área. No caso destes professorescursistas, a Plataforma Freire veio suprir essa lacuna e superar essa situação grave.

Tabela 01 - Tempo de Ensino dos Professores Cursistas do PARFOR - Campus IX Serrinha, (BA)

\begin{tabular}{ccc}
\hline Tempo de Ensino & Frequência & $\%$ \\
\hline Até 5 anos & 0 & 0 \\
6 a 10 anos & 2 & 10 \\
11 a 20 anos & 8 & 40 \\
acima de 20 anos & 10 & 50 \\
Total & 20 & 100 \\
\hline
\end{tabular}

Fonte: Pesquisa de Campo, 2014. Elaborado pelos autores. 
Tabela 02 - Tempo de Ensino de Geografia dos Professores Cursistas do PARFOR -

Campus IX - Serrinha (Ba)

\begin{tabular}{c|c|c}
\hline Tempo de Ensino & Frequência & $\%$ \\
\hline Não Ensina Geografia & 1 & 5 \\
até 03 anos & 5 & 25 \\
4 a 5 anos & 3 & 15 \\
6 a 10 anos & 5 & 25 \\
acima de 10 anos & 6 & 30 \\
Total & 20 & 100 \\
\hline
\end{tabular}

Fonte: Pesquisa de Campo, 2014. Elaborado pelos autores.

Dos professores-cursistas do Campus XXIV-Xique-Xique, $90 \%$ vivem na própria cidade sede do curso e 10\%, na zona rural do mesmo município. Dos 10 professores-cursistas pesquisados no Campus XXIV-Xique-Xique, 80\% tinham apenas ensino médio: 50\% deles haviam feito o magistério; $20 \%$, o curso de técnico em contabilidade; e 10\%, o curso técnico em agropecuária. Os 20\% restantes já tinham uma primeira graduação em Pedagogia e 10\% deles já tinham feito uma especialização. Neste sentido, a Plataforma Freire consistiu na primeira oportunidade de formação superior para maioria dos professores do ensino básico público no aludido município.

No caso de Xique-Xique, metade dos professores-cursistas atua em escolas urbanas e a outra metade ensina em escolas rurais. Da totalidade de professores-cursistas pesquisados, 60\% deles têm entre 5 e 10 anos de docência e 40\% ultrapassam os 10 anos em sala de aula (Tabela 03). No entanto, diferentemente do campus XI-Serrinha, a grande maioria dos professorescursistas atua há pouco tempo com a Disciplina Geografia. Como 90\% deles atuam há menos de 5 anos com Geografia, podemos deduzir que coincide com o tempo de realização do curso de licenciatura do PARFOR, ou seja, os discentes que estão fazendo o Curso de Licenciatura em Geografia já foram colocados em sala de aula para trabalhar com esta disciplina (Tabela 04). Vale ressaltar que, em nossa experiência profissional, já nos deparamos com professores sem formação 
superior assumindo turmas de geografia no ensino fundamental II e até mesmo no ensino médio.

Tabela 03 - Tempo de Ensino dos Professores Cursistas do PARFOR Campus XXIV Xique-xique (Ba)

\begin{tabular}{c|c|c}
\hline Tempo de Ensino & Frequência & $\%$ \\
\hline Até 5 anos & 0 & 0 \\
6 a 10 anos & 6 & 60 \\
acima de 10 anos & 4 & 40 \\
Total & 10 & 100 \\
\hline
\end{tabular}

Fonte: Pesquisa de Campo, 2014. Elaborado pelos autores.

Tabela 04 - Tempo de Ensino de Geografia dos Professores Cursistas do PARFOR Campus XXIV - Xique-xique (Ba)

\begin{tabular}{c|cc} 
Tempo de Ensino & Frequência & $\%$ \\
\hline Não Ensina Geografia & 2 & 20 \\
até 02 anos & 3 & 30 \\
03 a 05 anos & 4 & 40 \\
acima de 05 anos & 1 & 10 \\
Total & 10 & 100 \\
\hline
\end{tabular}

Fonte: Pesquisa de Campo, 2014. Elaborado pelos autores.

\subsection{Da Avaliação dos Cursos de Licenciatura em Geografia do PARFOR}

Buscamos realizar uma avaliação do curso, procurando conhecer a opinião dos professores-cursistas por meio de uma sondagem. No Campus XI-Serrinha, o resultado apontou que $45 \%$ dos discentes avaliaram o curso como ótimo, 35\% consideraram bom e apenas $20 \%$ consideraram como regular.

Esse resultado fica expresso quando os professores-cursistas apontam os pontos fortes do curso, dado que ajuda a compreender a avaliação realizada. Em resposta a uma questão aberta, 70\% dos professores apontaram a boa qualidade dos professores, $40 \%$ indicaram o bom trabalho da coordenação. Outras respostas apareceram na pesquisa, como a possibilidade de uma boa formação profissional (10\%), a construção de outra visão de Geografia (5\%) e a construção 
de senso crítico (5\%). Os professores-cursistas apontaram também, a existência de uma relação colaborativa e de parceria com os docentes que trabalharam no Curso de Licenciatura em Geografia do Campus XI/Serrinhaiii.

Coelho (2013) reforça a importância e a necessidade de uma relação colaborativa entre os professores formadores (no nosso caso, os professores da UNEB que trabalharam no PARFOR) e os professores da profissão (professorescursistas), centrada em uma articulação entre teoria e prática. Tardif (2006), por sua vez, destaca, em termos de exercício de relação colaborativa, a necessidade de considerar os saberes e as racionalidades dos estudantes como condição fundamental para a obtenção de resultados mais qualitativos no processo formativo.

A avaliação positiva do curso pode ser constatada também no conjunto de respostas reproduzidas a seguir: "Já me sinto mais seguro quando vou discutir alguns temas propostos pelo livro didático"; "Durante o curso nos ensinaram várias formas para trabalhar com Geografia"; "O curso me deixou mais preparada e confiante para trabalhar com Geografia"; "Minha visão de mundo agora é outra, o nível de conhecimento ampliou-se"; "Posso fundamentar minha prática em vários teóricos, dando-me maior confiança no que faço"; "Passei a ter uma compreensão maior dos fatos e conteúdos da Geografia e de como esta disciplina é realmente para fazer uma leitura de mundo."iv

Destaca-se que a totalidade dos professores se sente mais preparada e confiante para trabalhar com a Disciplina Geografia, reconhecendo que o curso ofereceu um arcabouço teórico e metodológico para fundamentar a prática docente na área de Geografia. Independentemente das dificuldades e dos problemas de concepção e funcionamento (que serão objeto do próximo tópico), a oportunidade de experienciar um curso de licenciatura trouxe mudanças importantes para a atuação profissional dos professores-cursistas, na medida em que os dotou de melhores condições para o exercício da docência, por meio do 
acesso a conteúdos e metodologias e a outras interpretações de mundo e do espaço geográfico.

Indagados sobre a contribuição que o curso ofereceu para sua formação profissional, os professores-cursistas assim responderam: “Me ajudou a compreender o mundo"; "Trouxe grande contribuição para entender o espaço geográfico"; "Como suporte para enriquecer nossas aulas"; "Contribuiu para o meu crescimento intelectual e profissional"; "Melhorei a minha prática, o meu senso crítico e a minha visão de mundo"; "Proporcionou uma reflexão sobre a minha práxis pedagógica"; “Fez com que eu mudasse minha prática em sala de aula."v

Os fragmentos selecionados permitem concluir que a experiência vivenciada, ao fazer um curso de Licenciatura em Geografia, produziu transformações qualitativas no modo como os professores-cursistas concebem e empreendem sua prática docente. As respostas indicam que estas transformações se desdobram em dois planos, ocorrendo (i) um movimento de reflexão sobre as concepções e práticas docentes e (ii) uma mudança na postura prática dos professores-cursistas frente ao processo de ensino-aprendizagem e ao mundo.

A apreciação das respostas anuncia um processo significativo, defendido pela literatura que trata da temática da formação de professores: o movimento de reflexão sobre a prática educativa dos professores-cursistas. Zeichner (2003) advoga a importância da prática reflexiva no processo de formação de professores, considerando que:

ao adotar o conceito de ensino reflexivo, muitas vezes há um compromisso, por parte dos formadores de professores, de ajudar educadores potenciais a internalizar, durante o treinamento o inicial, a disposição e a capacidade de estudar o seu ensino e melhorar durante toda a sua carreira (ZEICHNER, 2003, p. 42).

Em nosso caso de estudo, certamente, a dupla condição dos professorescursistas criou condições favoráveis para o movimento reflexivo, pois, de um 
lado, estavam posicionados como estudantes de um curso de licenciatura, sendo tencionados por conteúdos teóricos e metodológicos, e de outro, como professores em exercício, sendo colocados em um contexto de permanente colisão. Essa dupla condição pode ter potencializado as reflexões, na medida em que vivenciaram situações concretas em sala de aula.

Paiva (2003) oferece um conjunto de elementos para pensar e delinear o que se entende por professor reflexivo:

O professor, como prático 'reflexivo', desenvolve uma ação que não se limita à escolha dos meios e à resolução eficaz dos problemas. Delibera sobre os fins a serem atingidos numa ação segundo as características e contingências das situações de trabalho. O praticante reflexivo é capaz de gerir situações em parte indeterminadas, flutuantes, contingentes e negociar com elas criando soluções novas e otimizadas (PAIVA, 2003, p. 48-49).

Zeichner (1991) informa que os termos "prático reflexivo" e "ensino reflexivo" adquiriram enorme prestígio na literatura pedagógica e se tornaram, inclusive, slogans das reformas de ensino realizadas na América do Norte, Reino Unido, Austrália, Holanda, Espanha, Índia, Tailândia e Cingapura.

A condição de docentes do ensino básico dos nossos professores-cursistas, com larga experiência em sala de aula, como demonstramos nas tabelas 01 e 02, os colocam como sujeitos portadores de saberes profissionais. Tardif (2006, p. 264) informa a existência de saberes profissionais dos professores, afirmando que estariam "a serviço da ação [...] e é na ação que assumem seu significado e sua utilidade". Para o autor, esses saberes profissionais são raramente formalizados ou objetivados, mas são "saberes apropriados, incorporados, subjetivados, saberes que é difícil dissociar das pessoas, de suas experiências e situação de trabalho" (TARDIF, 2006, p. 265).

Os saberes profissionais dos professores tem sido objeto de reflexão teórica da denominada "epistemologia da prática profissional", que se volta para o estudo dos saberes utilizados pelos professores em seu trabalho cotidiano. A finalidade da "epistemologia da prática profissional" consiste em "revelar esses saberes, compreender como são integrados concretamente nas tarefas dos 
profissionais e como estes os incorporam, produzem, utilizam, aplicam e transformam em função dos limites e dos recursos inerentes às suas atividades de trabalho" (TARDIF, 2006, p. 256).

Para os professores-cursistas do Curso de Licenciatura em Geografia da Plataforma Freire, Campus XXIV-Xique-Xique, o nível do curso foi ótimo para 90\% dos pesquisados e para 10\% o nível foi bom, especialmente em decorrência do "preparo acadêmico dos professores na sua maioria."vi

Para detalhar e justificar essa avaliação extremamente positiva, os professores-cursistas apontaram um conjunto de pontos fortes, com destaque para: (i) a qualidade dos professores, resposta apresentada por 50\% dos pesquisados; (ii) possibilidade de rever as práticas pedagógicas e construção de nova visão de geografia, ambas com 30\% de frequência nas respostas; e (iii) possibilidade de boa formação profissional e boa estrutura do campus da UNEB, ambas com $20 \%$ de frequência.

A totalidade dos professores-cursistas se sente mais preparada para atuar como professores de Geografia, pois, mesmo reconhecendo que ainda apresentam limitações, o curso Ihes forneceu a possibilidade de "ampliação dos conhecimentos" e Ihes permitiu a construção de "aprendizagens teóricas e metodológicas", que qualificaram suas práticas pedagógicas. vii

Os professores-cursistas reconhecem que o Curso de Licenciatura em Geografia promoveu algumas contribuições para sua formação profissional: "Mudei minha forma de atuar no ensino de geografia escolar"; "Ajudou a ter mais segurança no meu trabalho, na teoria e na prática"; "Enriquecendo o nosso conhecimento e despertando um novo olhar geográfico"; "Pude elaborar um novo modelo de planejar e ministrar aulas"; "Na minha atuação em sala de aula, sintome confiante e com mais propriedade nas ações pedagógicas"; "As aulas [referese às aulas do curso de Licenciatura em Geografia do PARFOR] mudaram o ensino da minha prática."viii 
Os ganhos apontados pelos professores-cursistas do Campus XXIV-XiqueXique são mais de natureza prática e instrumental, geralmente dizendo respeito à contribuição que o curso trouxe para sua qualificação, especificamente para fins de atuação na docência em geografia. Nesse sentido, os fragmentos destacados ajudam a entender a avaliação positiva que eles fizeram do Curso de Licenciatura em Geografia.

\subsection{Das dificuldades e sugestões}

A contribuição que a experiência formativa do PARFOR ofereceu aos professores-cursistas parece inquestionável como vimos na seção anterior. No entanto, o Plano Nacional de Formação dos Professores da Educação Básica (PARFOR) também apresentou problemas estruturais e de natureza pedagógica e administrativa.

Respondendo a uma questão aberta, os professores-cursistas apontaram as principais dificuldades enfrentadas durante o curso. A maioria flagrante dos cursistas, equivalendo a $50 \%$ no Campus XI-Serrinha (Tabela 05) e a $40 \%$ no Campus XXIV-Xique-Xique (Tabela 06), considerou um obstáculo conciliar trabalho, estudo e família. Como se trata de um programa federal para qualificação de professores do ensino básico, o governo estadual e as prefeituras poderiam oferecer como contrapartida a redução da carga horária dos professores. Desse modo, a manutenção dos professores em sala se constituiu em um grande desafio para os professores-cursistas, especialmente por um problema de ordem prática: as/os estudantes do campus XI/Serrinha precisavam se dividir entre sala de aula na graduação como discentes, sala de aula no ensino básico como professores e as necessidades de deslocamento. Outro problema apontado por 30\% dos cursistas no Campus XI-Serrinha como agravante da situação foi a realização das aulas no final de semana. Vale ressaltar que as aulas funcionaram de forma concentrada no final de semana, fato que prejudica o 
processo de ensino-aprendizagem de professores-cursistas que passavam a semana toda trabalhando em suas unidades escolares.

Os argumentos em defesa de um professor reflexivo (apontada na seção anterior) e sobre a necessidade de uma educação de qualidade não podem estar dissociados da discussão sobre as condições de realização do processo de ensino-aprendizagem. Lima e Gomes (2005) reforçam a necessidade de considerar as condições objetivas de vida e de trabalho docente, sobretudo, o momento histórico que produz impactos diretos na prática educativa.

Os autores asseveram que a "reflexão não é uma atitude individual, ela pressupõe relações sociais, revela valores e interesses sociais, culturais e políticos [...]" (LIMA e GOMES, 2005, p. 164). Segundo os autores, os profissionais que não procuram refletir sobre sua atividade docente, geralmente, tendem a aceitar de maneira acrítica a realidade da escola.

Na perspectiva de Contreras (1997), um professor que reflete sobre sua ação, deverá refletir, simultaneamente, sobre como o modo de organização e o controle sobre o trabalho docente interferirá na prática educativa e em sua autonomia profissional. Portanto, não se trata de pensar a prática educativa por si só, isolada e descontextualizada da realidade sociopolítica em que os sujeitos estão envolvidos.

No caso do curso do Campus XI-Serrinha, como os professores eram oriundos de diversos municípios, apareceu como dificuldade o deslocamento dos cursistas de seus municípios de residência para o município polo, frequência que representou $25 \%$ dos pesquisados (Tabela 05). Neste caso, os professores eram oriundos dos munícipios de Biritinga $(18 \mathrm{~km})$, Barrocas (21 km), Teofilândia (22 km), São Domingos (73 km), Nova Soure (83 km), Santaluz (86 km) e Nordestina (168 km). Nesses casos, devem ser considerados não apenas a distância, mas a deficiência na oferta de transportes, especialmente no final de semana quando funcionavam as aulas. Os municípios de Barrocas e Biritinga, por exemplo, tem 
uma pequena frequência de ônibus intermunicipal (situação mais grave nos finais de semana), exigindo a busca por transporte alternativo, geralmente carros particulares que fazem os percursos sem a devida regularização junto ao poder público.

Tabela 05 - Principais dificuldades apontadas pelos Professores-Cursistas do Campus $\mathrm{XI}$ - Serrinha $(\mathrm{Ba})$.

\begin{tabular}{c|c|c}
\hline Dificuldades & Frequência & $\%$ \\
\hline Conciliar trabalho e estudo & 10 & 50 \\
Aulas no final de semana & 6 & 30 \\
Dificuldades de acompanhar o conteúdo & 6 & 30 \\
Deslocamento para a cidade polo & 5 & 25 \\
Instalações precárias & 1 & 5 \\
\hline
\end{tabular}

Fonte: Pesquisa de Campo, 2014.Elaborado pelos autores.

No caso do Campus XXIV-Xique-Xique, 30\% dos cursistas apontaram como dificuldade conseguir professores para ministrar as aulas, fato que se desdobrou em outra dificuldade indicada por $10 \%$ dos cursistas, isto é, o prolongamento do término do curso, que excedeu o tempo previsto para sua realização, originalmente previsto para 3 anos. Vale destacar que a cidade de Xique-Xique fica distante dos centros de formação de professores de geografia, especialmente das duas principais cidades baianas onde existem universidades com cursos de Geografia, que têm professores de curso superior disponíveis para trabalhar no PARFOR: Feira de Santana (470 km) e Salvador (585 km). Essa distância geográfica exigiu que o curso de Xique-xique concentrasse as aulas, repercutindo decisivamente na realização de atividades e impactando na qualidade da aprendizagem. Como os docentes residiam e trabalhavam predominantemente nessas duas cidades foi necessário concentrar as aulas nos finais de semana, 
para atender a disponibilidade dos docentes e para racionalizar os custos de deslocamento com o corpo docente.

Tabela 06 - Principais dificuldades apontadas pelos Professores-Cursistas do Campus XXIV - Xique-Xique (Ba).

\begin{tabular}{lcc}
\hline \multicolumn{1}{c|}{ Dificuldades } & Frequência & $\%$ \\
\hline Conciliar estudo, trabalho e família. & 4 & 40 \\
Dificuldades de encontrar professores para as & & \\
disciplinas & 3 & 30 \\
Prolongamento do término do curso & 1 & 10 \\
Dificuldades de recursos financeiros & 3 & 30 \\
Dificuldade de acompanhar o nível dos conteúdos & 3 & 30 \\
\hline
\end{tabular}

Fonte: Pesquisa de Campo, 2014. Elaborado pelos autores.

Outro problema que se mostrou representativo nas duas turmas de Licenciatura em Geografia foi a dificuldade para acompanhar o conteúdo trabalhado em sala de aula, equivalendo a 30\% dos/das professores-cursistas pesquisados/as, tanto no Campus XI-Serrinha quanto no Campus XXIV-XiqueXique. Vale destacar que muitos professores estavam sem estudar há mais de 10 anos e, em alguns casos, há mais de duas décadas. Considerando que a dificuldade com o conteúdo se apresentou de forma significativa, buscamos levantar em quais disciplinas os professores-cursistas enfrentaram mais dificuldades. As respostas da indagação sobre as disciplinas em que os cursistas enfrentaram mais dificuldades nos permitem duas conclusões: a primeira diz respeito à fragilidade na base matemática, pois $80 \%$ dos cursistas apontaram dificuldades de aprendizagem em cartografia e 40\%, em estatística.

Outra conclusão possível diz respeito à dificuldade com os componentes curriculares que compõem a chamada geografia física, uma vez que foram apontadas dificuldades em climatologia, geomorfologia e pedologia, respectivamente, 40\%, 10\% e 10\% (Tabela 07 e 08). Em nossa interpretação, esta segunda dificuldade decorre das lacunas formativas nas disciplinas que compõem as chamadas ciências naturais, pois a maior parte dos/das 
professores/cursistas fez magistério, curso que não oferece essas disciplinas. Esta é uma conclusão geral, pois nos dois cursos os resultados se mostraram alinhados.

Tabela 07 - Disciplinas que os professores-cursistas do Campus XI - Serrinha enfrentaram maior dificuldade

\begin{tabular}{c|c|c}
\hline Disciplinas & Frequência & $\%$ \\
\hline Estatística & 12 & 60 \\
Cartografia & 5 & 25 \\
Climatologia & 4 & 20 \\
Pedologia & 4 & 20 \\
Informática & 3 & 15 \\
Biogeografia & 2 & 10 \\
Região e Regionalização & 2 & 10 \\
\hline
\end{tabular}

Fonte: Pesquisa de Campo, 2014. Elaborado pelos autores.

Tabela 08 - Disciplinas em que os professores-cursistas do Campus XXIV - Xique-

Xique enfrentaram maior dificuldade

\begin{tabular}{c|c|c}
\hline Disciplinas & Frequência & $\%$ \\
\hline Cartografia & 8 & 80 \\
Estatística & 4 & 40 \\
Climatologia & 4 & 40 \\
Pluralidade Cultural & 2 & 20 \\
Geomorfologia & 1 & 10 \\
Pedologia & 1 & 10 \\
\hline
\end{tabular}

Fonte: Pesquisa de Campo, 2014. Elaborado pelos autores.

Como em todo processo avaliativo é fundamental pensar as soluções e alternativas. Um caminho profícuo foi ouvir os sujeitos envolvidos, que foram destinatários das ações e as vivenciaram profundamente. Neste sentido, buscamos levantar as sugestões que os professores-cursistas indicam para melhorar o PARFOR.

Geralmente, as soluções encontram-se alinhadas com os problemas vivenciados que mais afetaram o processo formativo. No Campus XI-Serrinha, a principal solução, apresentada por $30 \%$ dos pesquisados, foi não ofertar aula nos 
finais de semana. Outra sugestão, indicada por $20 \%$ dos cursistas, foi a liberação de parte da carga horária de sala de aula, especialmente para quem trabalha 40 horas. Essa sugestão está alinhada com a dificuldade de conciliar trabalho, estudo e família, que apareceu significativamente nas Tabelas 05 e 06 . Tais dificuldades revelam que os programas de formação docente, para além da dimensão formativa técnico-científica dos(as) docentes, precisam estar articulados com o contexto social, histórico, político, econômico e cultural em que está inserida a educação e as suas práticas. Assim, as dificuldades apresentadas pelos(as) estudantes da PARFOR, quando não consideradas no processo de formação desses sujeitos, que assumem diferentes papéis em sua vida cotidiana, trazem impactos na aprendizagem de conhecimentos profissionais referentes à docência e na constituição da identidade docente. Estes aspectos precisam ser considerados, pois, como idealiza esse programa de formação de professores(as) da Educação Básica em sua proposta formativa, os(as) professores(as) necessitam de tempo para ressignificar as suas identidades, para acomodar as inovações propostas no seu âmbito formativo-profissional e para assimilar as mudanças necessárias em suas práticas educativas.

Esse dado apresentado pelos estudantes da PARFOR, que estão em pleno exercício profissional, denuncia uma perversa lógica presente em algumas propostas formativas docentes que, por problemas estruturais e/ou de gestão, têm sacrificado os finais de semana dos(as) professores(as) e o convívio deles(as)com os seus familiares para estarem presentes nas aulas, atendendo, assim, às demandas apresentadas pelos diferentes componentes curriculares. Nessa direção, Barreto e Colares (2017, p. 321) explicam que:

[...] o fato dos professores terem que estudar em seu período de férias e recesso, estendendo-se ainda ao período letivo gera problemas/prejuízos à educação básica local e ainda um desgaste físico e emocional nos próprios professores que após este período exaustivo já tem que voltar às atividades pedagógicas sem seu merecido descanso. 
Diante desse cenário, as sugestões dos(as) estudantes precisam ser debatidas, em conjunto com a coordenação local, os gestores locais, a coordenação geral do programa frente à IES e a coordenação do curso, a fim de buscar soluções para esse problema e, assim, apresentar proposições que de fato possibilitem uma formação significativa aos estudantes-professores.

A redução do tempo de estágio apareceu em $15 \%$ das respostas. Vale destacar que existe uma polêmica sobre a condução do estágio, uma vez que os professores-cursistas defendem sua redução ou extinção, já que se trata de professores com larga experiência em sala de aula, conforme podem ser verificadas nas tabelas 01 e 02 . Contudo, o estágio tem um importante papel no processo formativo dos(as) professores(as), pois a proposta dessa atividade curricular do curso da PARFOR apresenta como intencionalidades, favorecer a compreensão da práxis educativa, contribuir para a construção da identidade profissional e valorizar os saberes docentes constituídos no processo formativoprofissional desses sujeitos, buscando potencializar sistematicamente a produção dos conhecimentos profissionais e científicos e a participação ativa relacionada às decisões e à gestão dos sistemas educativos (GHEDIN, 2006). Em síntese, a experiência de estágio tem um lugar de destaque no processo de formação docente, na medida em contribui com o desenvolvimento da capacidade crítica dos(as) estudantes, através de análises teoricamente fundamentadas e articuladas com a realidade em que as práticas e os fenômenos educativos se materializam.

Outras sugestões aparecem de forma menos representativa em termos percentuais (5\%), mas que não são menos importantes, a exemplo de maior tempo para elaboração do trabalho de conclusão do curso, diminuir o tempo de integralização do curso, elaboração individual do trabalho de conclusão do curso, melhorar a infraestrutura física e maior compromisso do poder público municipal. Essas indicações ocorreram em decorrência do tempo estabelecido para elaboração trabalho de conclusão do curso (TCC) e do modo como foram 
operacionalizadas as orientações, pois a feitura do TCC durou apenas um semestre, sendo elaborado em equipe de no máximo quatro componentes e conduzido apenas com cinco encontros mensais com o orientador. Em relação ao tempo de integralização, no projeto original, o curso estava previsto para durar três anos, no entanto, a maioria dos cursos do PARFOR ultrapassou cinco anos para sua integralização, em decorrência dos diversos problemas estruturais, a exemplo daqueles destacados na tabela 06.

No Campus XXIV-Xique-Xique, a principal sugestão é garantir o cumprimento do tempo de integralização curricular previsto, com $70 \%$ das respostas. Essa indicação se justifica pelo longo tempo de duração do curso e está vinculada às dificuldades de encontrar professores para as disciplinas, conforme demonstrado na Tabela 06. A segunda sugestão mais indicada, com $20 \%$ das respostas, é a adequação do cronograma de aulas à realidade dos alunos. Esta indicação diz respeito às aulas no final de semana e à necessidade de administrar estudo, trabalho e família (Tabela 06). Outras sugestões apareceram nas respostas de $10 \%$ dos cursistas, a exemplo da necessidade de financiamento para aula de campo, desconcentração de aulas em períodos curtos, instalação de laboratórios, melhoria na comunicação com os cursistas e evitar a oferta de aulas nos finais de semana.

Em síntese, as sugestões apresentadas pelos professores-cursistas encontram correspondência direta com os problemas vivenciados na trajetória do curso. As soluções foram respostas objetivas para problemas fundamentais, cujo conteúdo informa tanto as condições sociais e econômicas dos/as professores/as-cursistas, quantos as condições educacionais impostas pelo programa federal analisado, revelando um complexo contexto que envolveu a ação do governo municipal e estadual e às condições de operacionalização do programa pela Universidade do Estado da Bahia. 
Os dados, análises e reflexões sobre a experiência formativa dos dois cursos de licenciatura em Geografia, sobretudo, pela possibilidade de ouvir os sujeitos envolvidos, ofereceram uma avaliação dos cursos, levantando elementos e questões para que os gestores do Plano Nacional de Formação dos Professores da Educação Básica (PARFOR) possam corrigir os rumos do programa e fazer ajustes necessários.

Consideramos que a oferta de um curso de licenciatura para professores em serviço que não tiveram a oportunidade de se graduar é uma tarefa das mais relevantes. Trata-se, em termos gerais, da socialização do conhecimento produzido e sistematizado pela sociedade, com fins de formação profissional e qualificação da prática pedagógica. Consideramos também que a oferta de um curso presencial desta natureza atende melhor às demandas sociais e profissionais que os cursos de educação a distância, que proliferam Brasil afora e exigem uma autonomia dos sujeitos que, em nossa opinião, ainda não foi construída.

Neste sentido, a pesquisa (e nossas observações na condição de docentes no curso) revelou que os formandos do Plano Nacional de Formação dos Professores da Educação Básica (PARFOR), construíram melhores condições para o exercício da docência, assegurada com o acesso a conteúdos e metodologias e a outras interpretações de mundo e do espaço geográfico. Isso fica explicito nos dados e depoimentos transcritos neste artigo, mas também foi observado durante o processo formativo, por meio da participação nas aulas, no desenvolvimento das atividades, nas discussões em sala e nos resultados das avaliações de aprendizagem.

Portanto, mesmo se considerarmos os problemas enfrentados pelo PARFOR, não podem ser desconsideradas as mudanças qualitativas na vida e na trajetória formativa dos professores-cursistas. A grade curricular foi semelhante 
àquela adotada nos cursos regulares de Licenciatura em Geografia da Universidade do Estado da Bahia (UNEB). Os professores que trabalharam no PARFOR são, em sua maioria, docentes desta última instituição de ensino superior ou professores de outras Instituições de Ensino Superior (IES), especialmente as IES públicas. Os professores-cursistas utilizaram a infraestrutura da UNEB, inclusive com acesso às bibliotecas dos seus campi. Assim, apesar dos problemas enfrentados, não se pode deixar de reconhecer que a experiência de fazer um curso de graduação transformou a vida dos professores-cursistas. Certamente, eles/elas não são mais os/as mesmos/as após essa trajetória formativa, e suas práticas docentes estão sendo objeto de ressignificação.

Consideramos que a experiência da PARFOR, desenvolvida em diferentes cidades e regiões da Bahia, indica a importância da oferta de um curso superior em cidades distantes da capital do estado e dos centros urbanos que dispõem de licenciatura em Geografia, pois, viabiliza a formação específica de professores para o trabalho no ensino básico. A relevância deste programa, qualificando professores em serviço se torna mais expressiva com a constatação de que há significativo um número de professores ensinando geografia no interior da Bahia sem a formação superior exigívelix. Portanto, essa experiência impacta diretamente na qualidade do ensino público ofertado pelo interior da Bahia, que tradicionalmente apresentou lacunas na formação de professores, especialmente nos casos das disciplinas de formação específica, como é o caso da Geografia.

A despeito dos benefícios anunciados, que certamente produz rebatimentos locais e regionais na escola básica, os dados da pesquisa revelaram que há problemas estruturais, administrativos e pedagógicos que precisam ser enfrentados com vigor. O governo estadual e municipal precisa repensar a possibilidade de redução da carga horária em sala de aula dos professorescursistas. A Universidade do Estado da Bahia precisa criar condições mais propicias para qualificar o processo de ensino-aprendizagem, repensando a 
concentração de aulas nos finais de semana e o desenvolvendo atividades de apoio para suprir as carências de conteúdo apontadas pelos pesquisados.

Este texto sintetiza reflexões bastante gerais que carecem de maior aprofundamento, servindo muito mais de ponto de partida para estudos mais aprofundados e sistemáticos sobre essa experiência. Neste sentido, algumas questões podem ser levantadas para animar o debate e suscitar pesquisas: Quais os pressupostos e diretrizes que sustentam o Plano Nacional de Formação dos Professores da Educação Básica (PARFOR)? Como se estabeleceu a parceria entre a Universidade e os Governos federal, estadual e municipal no âmbito do PARFOR? Como os professores-cursistas ressignificaram sua prática pedagógica após essa experiência formativa? Quais os impactos dessa experiência formativa no cotidiano escolar? Que sentido essa experiência teve para os professorescursistas?

\section{REFERÊNCIAS}

BAHIA. Perfil dos Territórios de Identidade da Bahia. v. 3. Salvador: SEI, 2018.

BARRETO, ELIANE GRACY LEMOS ; COLARES, ANSELMO ALENCAR . O PARFOR na Universidade Federal do Oeste do Pará (UFOPA): perspectivas para a melhoria na práxis pedagógica. Revista HISTEDBR On-line, v. 17, p. 308-333, 2017.

COELHO NETO, A. S. Redes sociais e territorialidade no semi-árido brasileiro. Revista Geográfica de América Central, San José, v. 2, p. 1-18, 2011.

COELHO NETO, A. S. A trama das redes socioterritoriais no espaço sisaleiro da Bahia. $2013 a$. 426 f. Tese (Doutorado em Geografia). Instituto de Geociências, Universidade Federal Fluminense, Niterói - RJ.

COELHO NETO, A. S. Componentes definidores do conceito de território: a multiescalaridade, a multidimensionalidade e a relação espaço-poder. GEOgraphia, Niterói (UFF), v. 15, n. 19, p. 23-52, $2013 b$.

COELHO, P. J. S. Desenvolvimento profissional docente das professoras de educação infantil no contexto rural: desafios e perspectivas. In: SOUZA, E. C. de; PASSEGGI, M. da C.; VICENTINI, P. P. (Orgs.). Pesquisa (auto)biográfica: trajetórias de formação e profissionalização. Curitiba: Editora CRV, 2013, v. 1, p. 209-223.

CONTRERAS, D. J. La autonomia del professorado. Madrid (Espanha): Ed. Moarata, 1997. 
GHEDIN, E. Professor Reflexivo: da alienação da técnica à autonomia da crítica. In: PIMENTA, S. G.; GHEDIN, E. (Orgs.). Professor reflexivo no Brasil: gênese e crítica de um conceito. 3. Ed. São Paulo: Cortez Editora, 2005, p. 129-150.

GHEDIN, E. A articulação entre estágio-pesquisa na formação de professor-pesquisador e sue fundamentos. In: BARBOSA, Raquel Lazzari Leite. Formação de educadores: artes e técnicasciências e políticas. São Paulo: UNESP, 2006.

LIMA, M. do S. L.; GOMES, M de O. Redimensionando o papel dos profissionais da educação: algumas considerações. In: In: PIMENTA, S. G.; GHEDIN, E. (Orgs.). Professor reflexivo no Brasil: gênese e crítica de um conceito. 3. Ed. São Paulo: Cortez Editora, 2005, p. 163-186.

TARDIF. M. Saberes docentes e formação profissional. 7. ed. Petrópolis: Vozes, 2006.

PAIVA, E. V. de. A formação do professor crítico-reflexivo. In: PAIVA, E. V. (Org.). Pesquisando a formação de professores. Rio de Janeiro: DP \& A Editora, 2003, p. 47-66.

SOJA, E. W. Geografias Pós-Modernas: A reafirmação do espaço na Teoria Social Crítica. Rio de Janeiro: Jorge Zahar Ed., 1993.

ZEICHNER, K.M. Formando professores reflexivos para a educação centrada no aluno: possibilidades e contradições. In: BARBORA, R. L. L. (Org.). Formação de educadores. São Paulo: Editora UNESP, 2003, p. 35-55.

\footnotetext{
i No Plano Nacional de Formação dos Professores da Educação Básica (PARFOR), trabalhamos nos cursos de Licenciatura em Geografia, ofertados nos campi da Universidade do Estado da Bahia, nas cidades de Serrinha, Xique-Xique, Alagoinhas, Teixeira de Freitas, Salinas da Margarida. Ministramos as disciplinas Teoria da Geografia, Geografia Econômica, Geografia Política, História do Pensamento Geográfico (disciplinas ministradas pelo autor) e Fundamentos Teóricos da Ação Pedagógica III (disciplina ministrada pela co-autora).
}

ii Chamamos os discentes de professores-cursistas em decorrência de sua dupla condição: trata-se de professores que atuam na rede básica de ensino público e são estudantes do curso de Licenciatura em Geografia do PARFOR.

iii Esses dados foram obtidos com a aplicação do questionário aos professores-cursistas do Campus XISerrinha.

iv Fragmentos das respostas dos professores-cursistas ao questionário aplicado em outubro de 2014 (Campus XI-Serrinha).

${ }^{\vee}$ Fragmentos das respostas dos professores-cursistas ao questionário aplicado em outubro de 2014 (Campus XI-Serrinha).

vi Fragmento da resposta de um professor-cursista ao questionário aplicado em junho de 2014 (Campus XXIV-Xique-Xique).

vii Fragmentos de respostas dos professores-cursistas ao questionário aplicado em junho de 2014 (Campus XXIV-Xique-Xique).

viii Fragmentos de respostas dos professores-cursistas ao questionário aplicado em junho de 2014 (Campus XXIV-Xique-Xique). 
ix Este é um dado largamente conhecido com quem trabalha com educação básica no estado da Bahia e foi recorrentemente apontado pelo professores-cursistas dos dois cursos de Geografia da PARFOR. 